\title{
Gamma (40-100 Hz) Oscillation in the Hippocampus of the Behaving Rat
}

\author{
Anatol Bragin, ${ }^{1, a}$ Gábor Jandó ${ }^{1, b}$ Zoltán Nádasdy, ${ }^{1}$ Jamille Hetke, ${ }^{2}$ Kensall Wise, ${ }^{2}$ and György Buzsáki' \\ ${ }^{1}$ Center for Molecular and Behavioral Neuroscience, Rutgers, The State University of New Jersey, Newark, New Jersey \\ 07102 and ${ }^{2}$ Center for Integrated Sensors and Circuits, University of Michigan, Ann Arbor, Michigan 48109
}

The cellular generation and spatial distribution of gamma frequency $(40-100 \mathrm{~Hz}$ ) activity was examined in the hippocampus of the awake rat. Field potentials and unit activity were recorded by multiple site silicon probes (5- and 16-site shanks) and wire electrode arrays. Gamma waves were highly coherent along the long axis of the dentate hilus, but average coherence decreased rapidly in the CA3 and CA1 directions. Analysis of short epochs revealed large fluctuations in coherence values between the dentate and CA1 gamma waves. Current source density analysis revealed large sinks and sources in the dentate gyrus with spatial distribution similar to the dipoles evoked by stimulation of the perforant path. The frequency changes of gamma and theta waves positively correlated $(40-100 \mathrm{~Hz}$ and 5-10 Hz, respectively). Putative interneurons in the dentate gyrus discharged at gamma frequency and were phase-locked to the ascending part of the gamma waves recorded from the hilus. Following bilateral lesion of the entorhinal cortex the power and frequency of hilar gamma activity significantly decreased or disappeared. Instead, a large amplitude but slower gamma pattern $(25-50 \mathrm{~Hz}$ ) emerged in the CA3-CA1 network. We suggest that gamma oscillation emerges from an interaction between intrinsic oscillatory properties of interneurons and the network properties of the dentate gyrus. We also hypothesize that under physiological conditions the hilar gamma oscillation may be entrained by the entorhinal rhythm and that gamma oscillation in the CA3-CA1 circuitry is suppressed by either the hilar region or the entorhinal cortex.

[Key words: hippocampus, gamma oscillation, $40 \mathrm{~Hz}$, theta, unit activity, behavior, hilar region]

The cellular generation of two hippocampal EEG patterns, theta and sharp waves (SPW), has been studied in detail (Buzsáki et al., 1983, 1986, 1992; Buzsáki, 1986; Fox and Ranck, 1986; Bland et al., 1990; Brankack et al., 1993). A third known pattern is the low-amplitude fast activity or gamma oscillation (40-100

\footnotetext{
Received Dec. 27, 1993; revised May 18, 1994; accepted June 23, 1994.

We thank Drs. J. J. Chrobak, W. J. Freeman, C. M. Gray, T. F. Freund J., Tepper, and X.-J. Wang for discussion and their comments on the manuscript. This work was supported by NIH, HFSP and the Whitehall Foundation.

Correspondence should be addressed to György Buzsáki, Center for Molecular and Behavioral Neuroscience, Rutgers University, 197 University Avenue, Newark, NJ 07102

'Permanent address: Institute of Experimental and Theoretical Biophysics, Puschino, Russia.

'Permanent address: Department of Physiology, Medical School, Pécs, Hungary. Copyright (C) 1995 Society for Neuroscience $0270-6474 / 95 / 150047-14 \$ 05.00 / 0$
}

$\mathrm{Hz}$ ) which occurs with largest power in the hilus of the dentate gyrus (Stumpf, 1965; Buzsáki et al., 1983; Boeijinga and Lopes da Silva, 1988; Skaggs et al., 1991; Leung, 1992). Synchronous gamma activity has been extensively studied in several other structures of the brain (Freeman and Skarda, 1985; Gray et al., 1989; Gray, 1993, 1994; Llinás and Ribary, 1993; Freeman 1994; Singer, 1994). It has been hypothesized that the temporal conjunction of sensory neurons in the gamma frequency range represents the subjective experience referred to as the percept (Gray et al., 1989). To date, no function has been assigned to the gamma pattern of the hippocampal hilar region. The dentate gyrus offers a unique opportunity to study the mechanisms underlying the generation of this fast rhythm, since the inputoutput and intrinsic connections of the dentate circuitry and its neuronal types are relatively well known. In the present experiments we examined the cellular-synaptic generation of gamma activity using multiple site recordings of field potentials and unit activity in the freely behaving rat. Some of the results have been presented in an abstract form (Bragin ct al., 1993).

\section{Materials and Methods}

Animals and surgery. Forty-five male and female rats $(300-450 \mathrm{gm})$ of the Sprague-Dawley strain were used in this study. The rats were anesthetized with a mixture $(4 \mathrm{ml} / \mathrm{kg})$ of ketamine $(25 \mathrm{mg} / \mathrm{ml})$, xylazine $(1.3$ $\mathrm{mg} / \mathrm{ml})$, and acepromazine $(0.25 \mathrm{mg} / \mathrm{ml})$. Pairs of stainless steel wires (100 $\mu \mathrm{m}$ in diameter) with $0.5 \mathrm{~mm}$ vertical tip separation were placed in the angular bundle on the right or both sides to stimulate the medial perforant path afferents to the hippocampus (AP $=-7.0 \mathrm{~mm}$ from bregma, $\mathrm{L}=3.5 \mathrm{~mm}$ from midline, and $\mathrm{V}=3.0 \mathrm{~mm}$ ). Another electrode pair was placed into the ventral hippocampal commissure $(\mathrm{AP}=-0.8$, $\mathrm{L}=0.5, \mathrm{~V}=-4.2)$ to stimulate the commissural afferents to the CAl3 regions and the dentate gyrus.

Recording and data analysis. Three different recording electrodes were used: stationary wire electrodes, microelectrode arrays, and 16-site recording silicon probes, as described in the accompanying article (Ylinen et al., 1994). Stationary electrodes (two to four $60 \mu \mathrm{m}$ tungsten wires) were implanted in the strata pyramidale and radiatum of $\mathrm{CAl}$ and the molecular layer and hilus of the dentate gyrus bilaterally (AP $=-3.0$, $\mathrm{L}=2.6, \mathrm{~V}=-2.4,-3.0$ ). Microelectrode arrays consisted of four to eight tungsten wires $(20$ or $60 \mu \mathrm{m}$ in diameter). Two or three $20 \mu \mathrm{m}$ wires or a single $60 \mu \mathrm{m}$ wire was inserted into the parallel array of fused silica tubes with $0.3 \mathrm{~mm}$ horizontal separations. The wires protruded 3 to $4 \mathrm{~mm}$ from the guiding tubes. The $20 \mu \mathrm{m}$ wires within a single silica tube were glued together with varnish. A $3.5 \mathrm{~mm}$ by $1 \mathrm{~mm}$ slot was drilled into the skull above the dorsal hippocampus along the longitudinal or the traverse (dentate-CA3) axis of the structure. For simultaneous recording of field potentials and unit activity in different layers, silicon probes micromachined with thin-film technology (Wise and Najafi, 1991) were used in 11 rats (for details, see Fig. 1 of Ylinen et al., 1994). The parallel wire arrays and silicon probes, attached to a movable headstage, were inserted into the neocortex or corpus callosum during surgery. Following recovery, the tips were gradually lowered into the hippocampus. During the experiment the evoked field potentials 


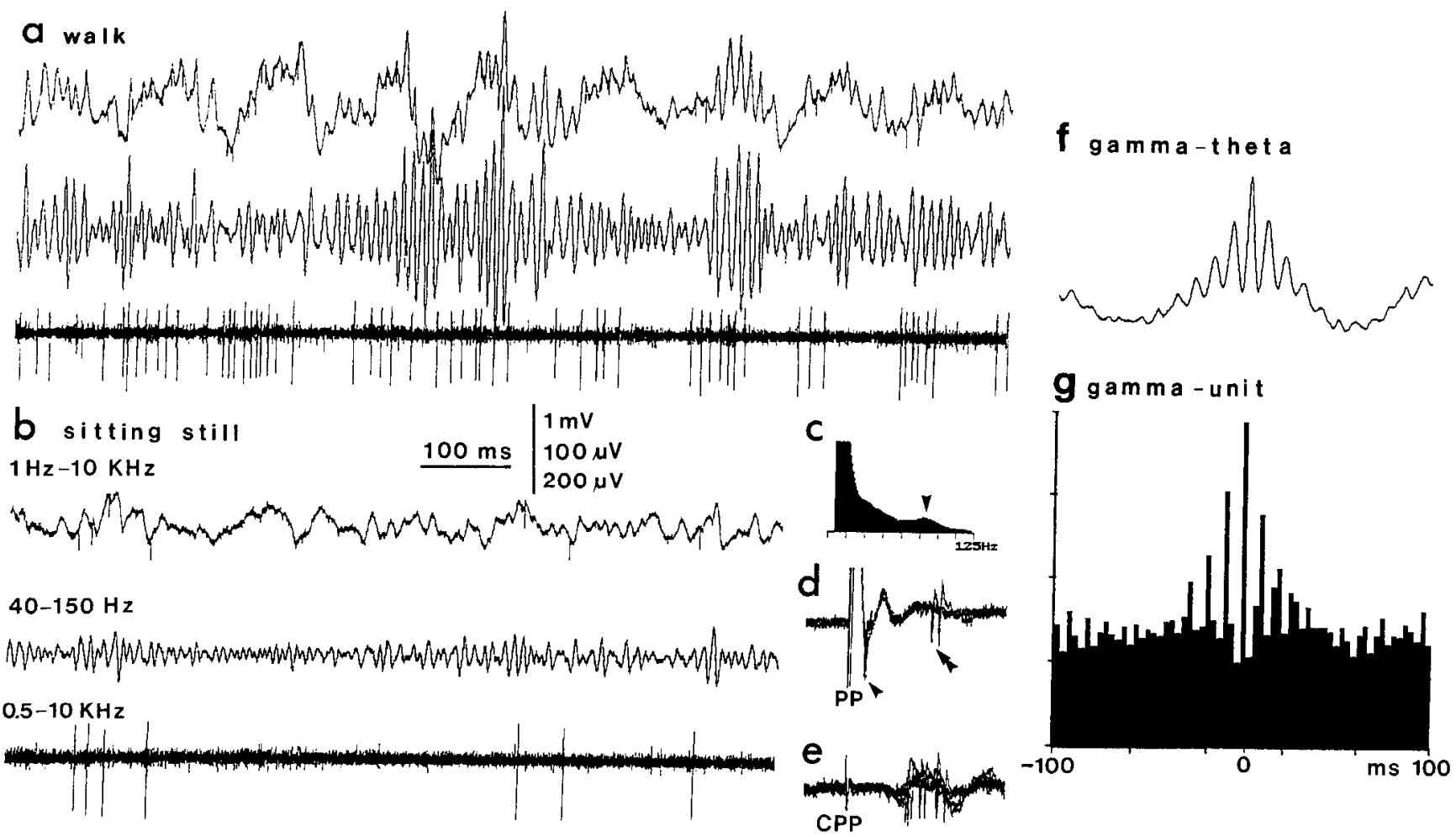

Figure 1. Gamma activity in the hilar region. Microelectrode recording during exploratory walking $(a)$ and sitting motionless $(b)$. Upper trace, wide band recording. Middle and lower traces, gamma activity $(40-150 \mathrm{~Hz})$ and unit firing $(500 \mathrm{~Hz}$ to $5 \mathrm{kHz})$, respectively. Note theta- and gammarelated modulation of the isolated neuron. $c$, Power spectrum of the EEG during walking. Arrow points to the power peak of gamma activity (80 $\mathrm{Hz}$ ). Power peaks at lower frequencies are clipped. $d$, Direct (feed-forward) excitation of the interneuron by stimulating the ipsilateral perforant path $(P P)$. Note short latency discharge of the cell (arrow, $1.7 \mathrm{msec}$ ) and occasional late firing (double arrow). $e$, In response to stimulation of the contralateral perforant path (CPP) the interneuron fired at the onset of the field response. $d$ and $e$ are seven superimposed, filtered ( $>500 \mathrm{~Hz}$ ) traces. $f$, Event related average of the wide band activity. The averager was triggered by the peaks of successive gamma waves. Note that the largestamplitude oscillation of gamma occurs on the positive portion of the averaged theta wave. $g$, Cross-correlogram of unit firing and peaks of the gamma waves. Note the relationship between averaged field $(f)$ and unit discharges $(g)$.

helped guide the microelectrodes. Two stainless steel watch screws driven into the bone above the cerebellum served as indifferent and ground electrodes. Recording and data processing methods were the same as described in detail in the accompanying article (Ylinen et al., 1994).

Spike separation and analysis. A Haar transformation was performed on the digitally filtered $(500 \mathrm{~Hz}$ to $5 \mathrm{kHz}$ ) traces to locate the occurrence of spike events (Yang, 1988). The spike events were identified by the factorial description of their shape ("feature") characteristics. Event sorting was carried out by an IBM RS6000 using a perceptron version of the incremental conceptual clustering procedure (SpikePerceptron, MUA Technology BT, Pécs, Hungary). For visual display, the spike occurrences within the same target cluster were superimposed and projected relative to the reference event (Ylinen et al., 1994). The crosscorrelograms were calculated from the cumulative number of spikes. Isolation of single units within and across clusters was verified by clear refractory periods ( $2-3 \mathrm{msec}$ ) in their interspike interval histograms. In addition, the temporal dynamics of single cells was examined by constructing "return maps" by plotting the interspike intervals $\left(x_{i}\right)$ against the next interspike interval $\left(x_{i+1}\right)$ (Siegel, 1990).

Several isolated units were identified by physiological criteria. Units that discharged at a shorter latency than the population spike and responded with two or more action potentials in response to perforant path or commissural stimulation were classified as interneurons (e.g., Figs. 1d,e, 6b; Fox and Ranck, 1981; Buzsáki and Eidelberg, 1982). These cells typically fircd at high rates $(>15 \mathrm{~Hz})$ and discharged in rhythmic groups at the field theta frequency. Units that displayed spontaneous complex burst patterns were classified as pyramidal cells or mossy cells (Ranck, 1973; Soltész et al., 1993). Complex-spike cells typically fired at less than $1 \mathrm{~Hz}$. Physiological criteria for the identification of granule cells are controversial (Mizumori et al., 1989; Buzsáki and Czéh, 1992) and no criteria have been established for the separation of the various cell groups in the hilus (Amaral, 1978).
In some cases field events were also clustered by the SpikePerceptron sorting program. These field events either served as reference events for cross-correlation analysis with units or as target events referenced to other field events (e.g., gamma pattern vs theta).

Entorhinal cortex lesion. In two groups of rats the entorhinal cortex was removed bilaterally. In the first group $(n=6)$, the electrodes were placed first, and the lesion was made after the completion of the physiological tests. In the second group $(n=5)$, the lesion was made first and electrodes were implanted 3 months later. The lesion was made under halothane $(2.5 \%)$ gas anesthesia. The bone above the entorhinal and perirhinal cortex was removed, and the dura was cut. The gray matter and the underlying white matter was aspirated under microscopic vision. The resulting cavity was filled by Gelfoam and the wound was closed.

Histological procedures. Following completion of the experiments the rats were deeply anesthetized and perfused through the heart first with cacodylate-buffered saline (pH 7.5) followed by a cacodylate-buffered fixative containing $4 \%$ paraformaldehyde and $5.9 \%$ calcium chloride (pH 7.5). Brains were left in situ for $24 \mathrm{hr}$, removed, and then postfixed in the same solution for 1 week. The brains were sectioned with the probes left in the brain on a vibratome at $100 \mu \mathrm{m}$ in the coronal plane. The sections were stained with the Gallyas silver method (Gallyas et al., 1990).

\section{Results}

Hippocampal EEG and unit activity were recorded in the awake and sleeping rat. Similar to earlier observations, theta activity occurred during exploratory behaviors, including walking, sniffing and rearing, and the paradoxical phase of sleep (Vanderwolf, 1969). During awake immobility, drinking, grooming, drowsi- 


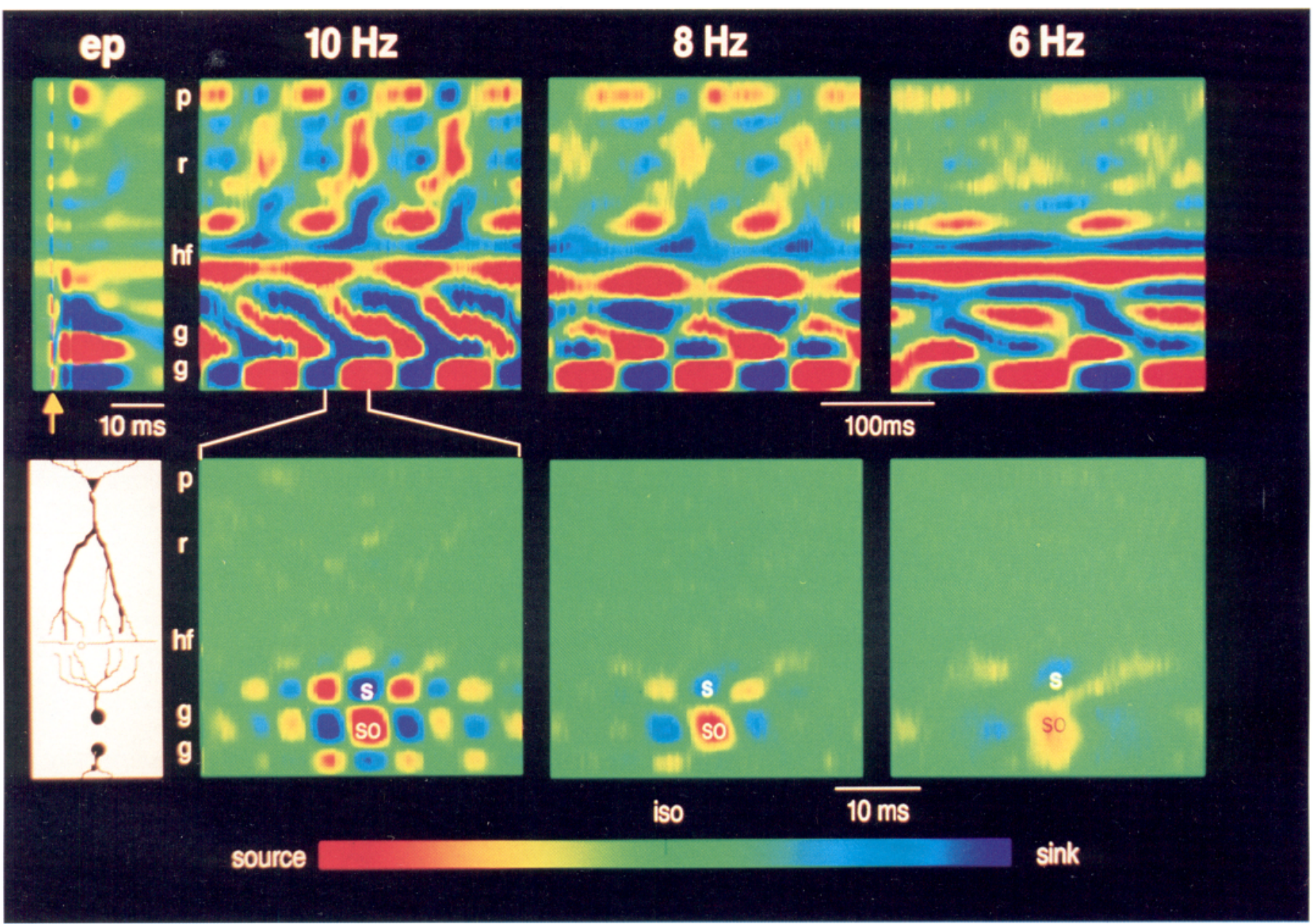

Figure 2. CSD maps of evoked responses (ep) to perforant path stimulation (yellow arrow), theta activity at three different frequencies (upper panels) and corresponding fast activity (lower panels). Sinks (inward currents) and sources (outward currents) are indicated by cold and warm colors, respectively. iso, Zero current flow. Note gradually shifting sinks and sources with depth during theta (upper panels). The lower panels are from the same EEG epochs as theta activity after bandpass filtering $(40-150 \mathrm{~Hz})$. Note identical positions of sinks $(s)$ and sources $(s o)$ for the various frequencies of theta $(10,8$, and $6 \mathrm{~Hz}$, upper panels $)$ and for the corresponding high-frequency oscillations $(100,60$, and $40 \mathrm{~Hz}$ dominant frequencies, lower panels). Note also the similar direction of changes in frequency for theta and fast activity. $p$, CAl pyramidal layer; $r$, stratum radiatum; $h f$, hippocampal fissure; $g$, granule cell layer.

ness, and slow wave sleep theta activity was replaced by irregular patterns. These included slow delta waves, sleep spindles, sharp waves (SPW), and dentate spikes recorded from the CAl and dentate regions (Buzsáki et al., 1983; Buzsáki 1986; Bragin et al., 1992).

\section{Gamma oscillations (40-100 $\mathrm{Hz})$ in the dentate gyrus and CAl region}

Gamma oscillation and theta activity was recorded during spontaneous walking and paradoxical phase of sleep. Figure 1 illustrates typical records of wideband and filtered field patterns and interneuronal activity in the hilus during exploratory walking and sitting motionless. During theta-associated behaviors, such as exploration, sniffing, rearing and the paradoxical phase of sleep the amplitude of gamma activity was larger than during sitting still and other consummatory behaviors (Fig. 1 $a, b$ ). The activity of putative interneurons in the hilus closely reflected these field potential changes; they fired rhythmically and at a higher rate during theta-associated behaviors (Fig. 1 $a, b$, lower traces). In addition, the filtered high-frequency activity showed a covariance with theta activity (Fig. $1 a, b$, middle traces, and Fig. 1f). Spectral analysis of the field activity confirmed the visual observations. The power of gamma activity above $40 \mathrm{~Hz}$ was significantly larger during theta-associated behaviors than during immobility, drowsiness and slow wave sleep (not shown), confirming earlier observations (Leung et al., 1982; Buzsáki et al., 1983; Bullock et al., 1990). Subsequent analysis therefore concentrated on the gamma frequency band $(40-100 \mathrm{~Hz})$ associated with theta waves. The depth profiles of the power, phase and coherence of theta and gamma patterns were different (cf. Fig. 9, before lesion graphs). The largest power of theta occurred at the level of the hippocampal fissure with a second peak in the hilus of the dentate gyrus (Fig. 9a). In contrast, the power of gamma oscillations was several times larger in the hilus than at any other level (Fig. 9d). Theta was highly coherent throughout the CA1-dentate axis, whereas coherence values of gamma dropped below significant levels outside the hilar region (Fig. $9 b, e)$. Theta waves showed a gradual phase shift in the CA1 region and a further $30-90^{\circ}$ shift between the dentate molecular layer and the hilus. Gamma waves, on the other hand, displayed 
A
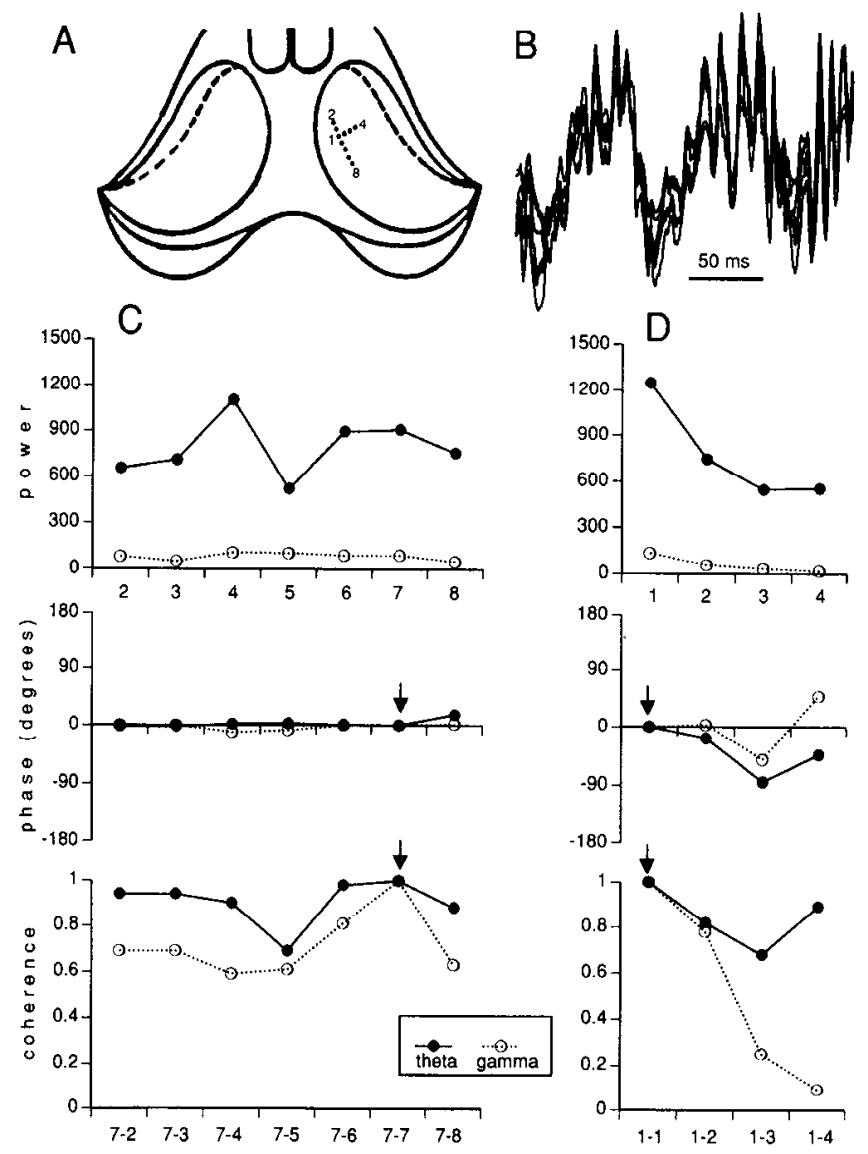

Figure 3. Coherence of gamma activity in the longitudinal and transverse directions. $A$, Dorsal view of the hippocampus. Electrodes 2-8 (longitudinal) and 1-4 (transversal) are indicated by black dots. $B$, Superimposed traces of simultaneously recorded signals from the hilus in the longitudinal axis (electrodes $2-8$ in $A$ ). Note similar modulation of the waveforms. $C$ and $D$, Power, phase, and coherence of theta and gamma waves in the longitudinal axis of the hilar region. Arrows indicate the reference electrode (site 7 in $C$ and site 1 in $D$ ). $D$, Power, phase, and coherence of theta and gamma waves in the transverse (subiculofimbrial) direction. Note high coherence and near-zero phase shift of both theta and gamma in the longitudinal axis and the steep decrease of coherent activity in the transversal direction. Power: integrated 6$12 \mathrm{~Hz}$ and $40-100 \mathrm{~Hz}$. Phase and coherence values: $8 \mathrm{~Hz}$ and $80 \mathrm{~Hz}$.

a steep phase reversal across the granule cell layer (Fig. $9 c, f$ ). These changes were observed in all rats with 16-site silicon probes $(n=11)$.

The differences in the frequency domain analysis were also reflected by the CSD maps for the theta and gamma patterns (Fig. 2). In confirmation of previous findings, CSD analysis of theta waves showed several, phase-shifted dipoles in the CAI region and the dentate gyrus (Buzsáki et al., 1986; Brankack et al., 1993). Analysis of gamma waves $(40-100 \mathrm{~Hz})$ revealed a large inward current (sink) in the middle third of the molecular layer with an cqually large source in the granule cell layer (Fig. 2 , lower panels). The spatial position of the sink-source pair of the gamma oscillation was similar to the dipole representing the medial perforant path-induced EPSCs of granule cells (Fig. 2, ep). The gamma band-concurrent source at the level of granule cell somata may therefore reflect a passive return current associated with perforant path induced EPSCs (active sink) and/ or active outward current due oscillatory activity of inhibitory interneurons. Recordings from identified interneurons support the latter possibility (see helow). The extracellular currents discussed here were consistently present in all 11 animals with multiple site probes.

In contrast to the large currents associated with gamma waves in the dentate gyrus, sink-source pairs in the CAl region were not readily visible in the CSD figures. Cross-correlation of the hilar gamma waves with simultaneously recorded single units or multiple units of CA1 neurons resulted in flat correlograms $(n=3$ rats). Coherence values between gamma waves derived from the hilar area and the CAl region were generally low $(<0.3)$ when long EEG epochs were analyzed. However, visual inspection of the original EEG records occasionally revealed epochs with large-amplitude, high-frequency patterns in the CA1 region. Coherence spectra performed on short epochs $(1 \mathrm{sec})$ revealed that gamma wave coupling between the dentate hilus and the CAI region could be high at times. In the short epoch comparisons coherence values ranged from 0.2 to 0.8 . Overall, these observations indicate that largest-amplitude gamma activity occurs in the hilar region and that coupling between the dentate and CAl regions is a rare event in the intact rat.

\section{Spatial coherence of gamma oscillation}

In addition to the dorsoventral direction, the longitudinal and transverse (subiculofimbrial) extent of gamma waves was also measured (Fig. 3). Simultaneous recording from four to eight sites in the longitudinal axis of the hilus showed very similar patterns (Fig. 3B). Although the power values derived from the different electrodes varied somewhat, the shapes of the power spectra were virtually identical. The phase shift remained within $\pm 20^{\circ}$ for all frequencies up to $125 \mathrm{~Hz}$ and coherence values were higher than 0.6 at these frequencies (Fig. $3 C$ ). Supcrimposed records derived from electrodes placed $0.9-2.1 \mathrm{~mm}$ from each other in the hilus displayed very little variability $(n=5$ rats). Comparison of the histological location of the electrode tips with electrical activity suggested that vertical or lateral mismatch of the electrodes relative to the center of the hilus contributed significantly more to the variability than distance. Crosscorrelograms between unit firing and field activity resulted in strong modulation independent of whether the gamma waves were derived locally or from a distant hilar electrode (up to 2.1 $\mathrm{mm})$.

In contrast, when the electrodes were positioned in the transverse plane electrical patterns derived from those sites were markedly different. The power of both theta and gamma bands decreased in the lateral (fimbrial) direction ( $n=4$ rats). Whereas coherence of theta activity remained high, coherence values of gamma waves decreased rapidly in the hilus-CA3 axis (Fig. $3 D$ ). These observations indicate that gamma oscillation is highly coherent in the septotemporal axis of the hilus, but the coupling between the dentate and CA 3 regions is very low.

\section{Theta modulation of gamma oscillation}

Despite the differences in the laminar profiles of theta activity and gamma oscillation, the two patterns covaried in several respects. The frequency of both theta and gamma oscillation varied over a wide range during both walking and the paradoxical phase of sleep. When theta epochs of different mean frequencies $(6,8$, and $10 \mathrm{~Hz})$ were selected manually from long records, the power peaks in the gamma band corresponded to $50 \mathrm{~Hz}, 80 \mathrm{~Hz}$, and $100 \mathrm{~Hz}$, respectively. This frequency change of gamma oscillation is reflected by the longer intervals of the repetitive the sink-source pairs with decreasing theta frequency 
(Fig. 2, lower panels). Such correlated shifts of theta and gamma frequencies were made on five additional animals. These observations suggest that similar mechanisms are involved in the frequency modulation of theta and gamma waves.

The amplitude of gamma oscillation varied as a function of the theta cycle. Such a cyclic variation of the gamma waves could often be revealed visually in hilus-derived records (e.g., Fig. 1a). Three different methods were used to quantitatively evaluate the phase coupling between theta and gamma waves. First, the digitally filtered gamma waves $(40-150 \mathrm{~Hz})$ were rectified, smoothed and integrated. The resulting analog curve ("power" of gamma) was then cross-correlated with the phase of theta ( $n=4$ rats). The resulting cross-correlograms revealed that power peaks of gamma preferentially occurred on the positive phase of the local theta waves (data not shown). The second method cross-correlated the peaks of gamma waves with theta waves. In one version the peaks of the filtered gamma waves twice as large as the background "gamma" during immobility were detected (reference events) and the resulting pulses were used to average the wide band signal $(n=24$ averages in 15 rats). As illustrated in Figure $1 f$, this method also indicated that large-amplitude gamma waves occur preferentially on the positive peaks of the theta cycle. In the second version of this approach gamma waves were identified by the factorial description of their shape characteristics and clustered into separate groups and were cross-correlated with the zero-crossings of theta waves (reference events). Such comparisons were carried out in three animals. In all three cases the clusters with the largestamplitude gamma waves were associated with the positive peaks of locally derived theta (Fig. $4 b, d$ ). The lack of correlation between small-amplitude clusters and theta (Fig. $4 c$ ) suggests that small-amplitude fast waves may have derived from the filtering procedure or represented extracellular currents generated independently from the larger-amplitude gamma pattern. Third, the wide band field activity was averaged by the spike occurrence of fast firing interneurons ( $n=8$ units in six rats). The spiketriggered averaging technique confirmed the findings of the previous two methods. Overall, the above analyses revealed that (1) the gamma oscillation was phasically modulated by the theta cycle and that (2) the largest power of gamma activity coincided with the positive portion of the theta waves derived from the hilus.

\section{Gamma wave-unit correlations}

In order to evaluate the local contribution of neuronal activity to the gamma field waves, neuronal firing was cross-correlated with the filtered $(40-150 \mathrm{~Hz})$ field activity. In the dentate region, three major classes of neurons can be distinguished: granule cells, hilar interneurons, and slow firing pyramidal cells and mossy cells. Due to the lack of clear-cut physiological criteria of the granule cells in vivo (Mizumori et al., 1979; Buzsáki and Czéh, 1992), our analysis was confined to the cell types located in the hilar region. Cross-correlograms of multiple unit activity and single unit activity in the hilus with gamma waves showed a strong amplitude modulation. Nine neurons were physiologically identified as isolated interneurons. These interneurons fired multiple action potentials in response to perforant path or commissural stimulation (e.g., Figs. 1d,e, 6B) and had a clear $2-5 \mathrm{msec}$ refractory period in their autocorrelograms.

Interneurons had two preferred frequency ranges in their autocorrelograms: at theta $(5-10 \mathrm{~Hz})$ and gamma $(40-100 \mathrm{~Hz})$ bands. All of them discharged preferentially on the ascending a

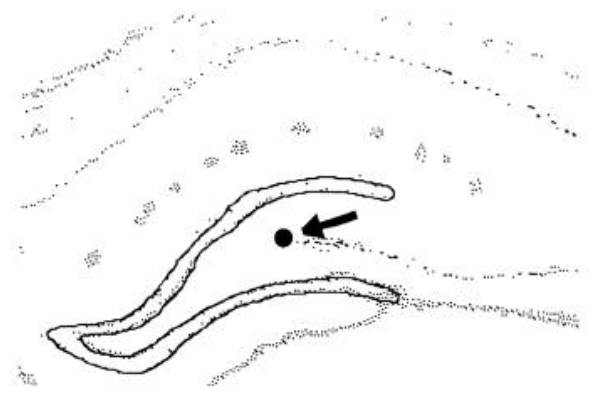

b
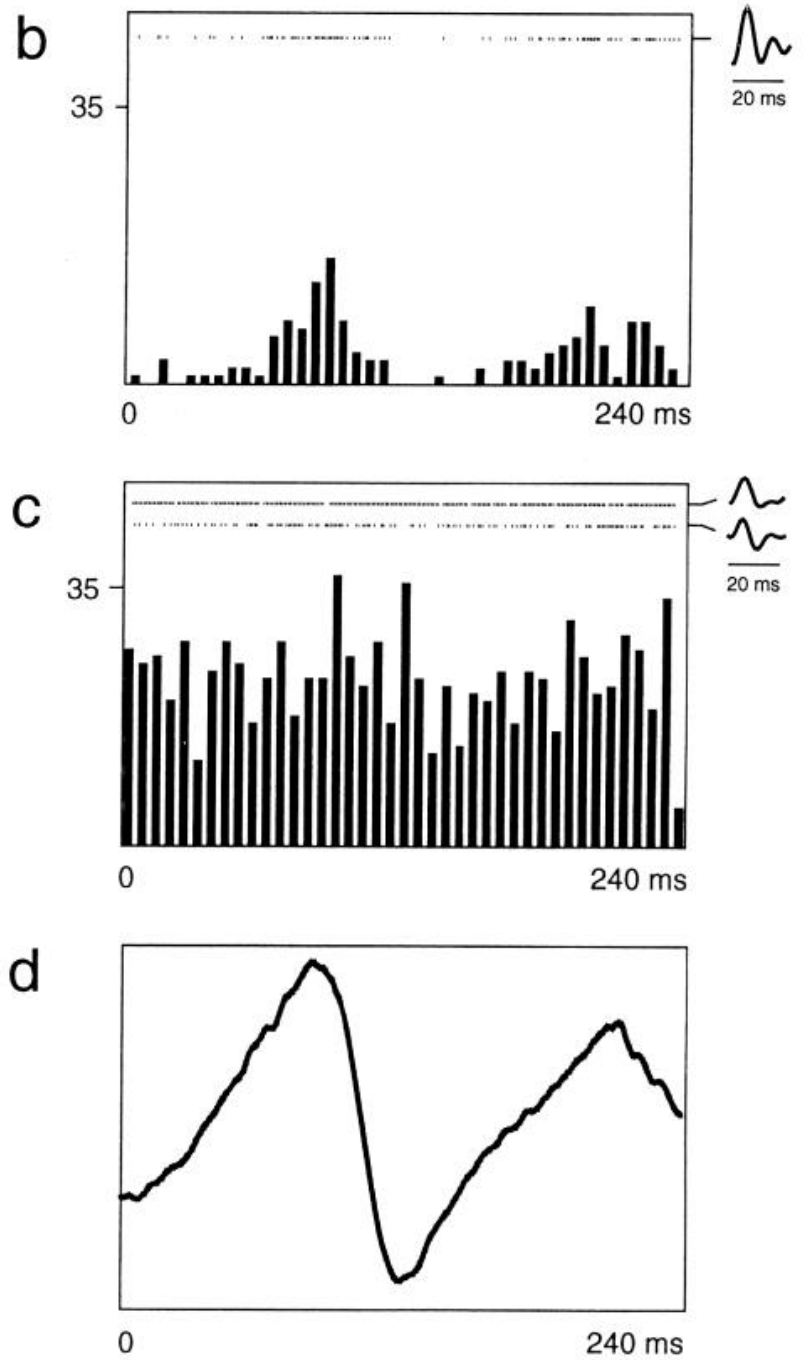

Figure 4. Theta modulation of gamma activity. EEG recorded from a hilar electrode (arrow in $a$ ) was filtered $(40-150 \mathrm{~Hz})$ and the gamma waves ( $20 \mathrm{msec}$ epochs) were clustered, based on their amplitude and waveshape characteristics. Three averaged clusters are shown right of the boxed areas in $b$ and $c$. The resulting independent wave clusters were then cross-correlated with theta waves $(d)$. Individual wave events are represented as dots above the cross-correlograms in panels $b$ and $c$. Note that the large-amplitude cluster $(a)$ was phase locked to the positive portion of the locally derived theta pattern $(d)$.

(negative to positive) phase of the locally derived gamma waves. In the experiment shown in Figure 5, unit and field activity was recorded simultaneously at three different sites in the dentate gyrus. Gamma waves were clustered into four groups, as de- 


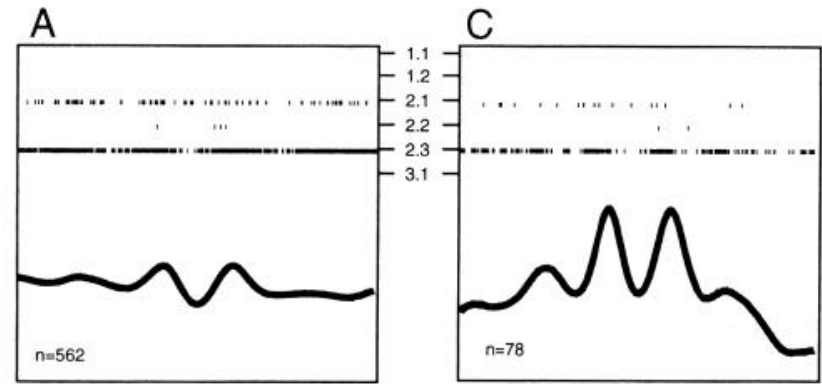

B

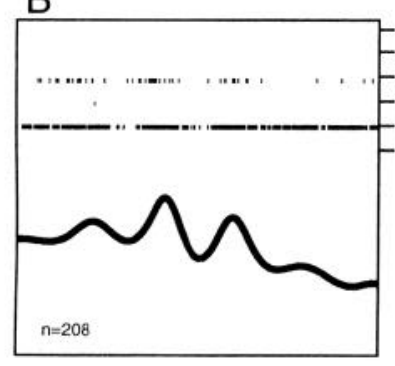

D
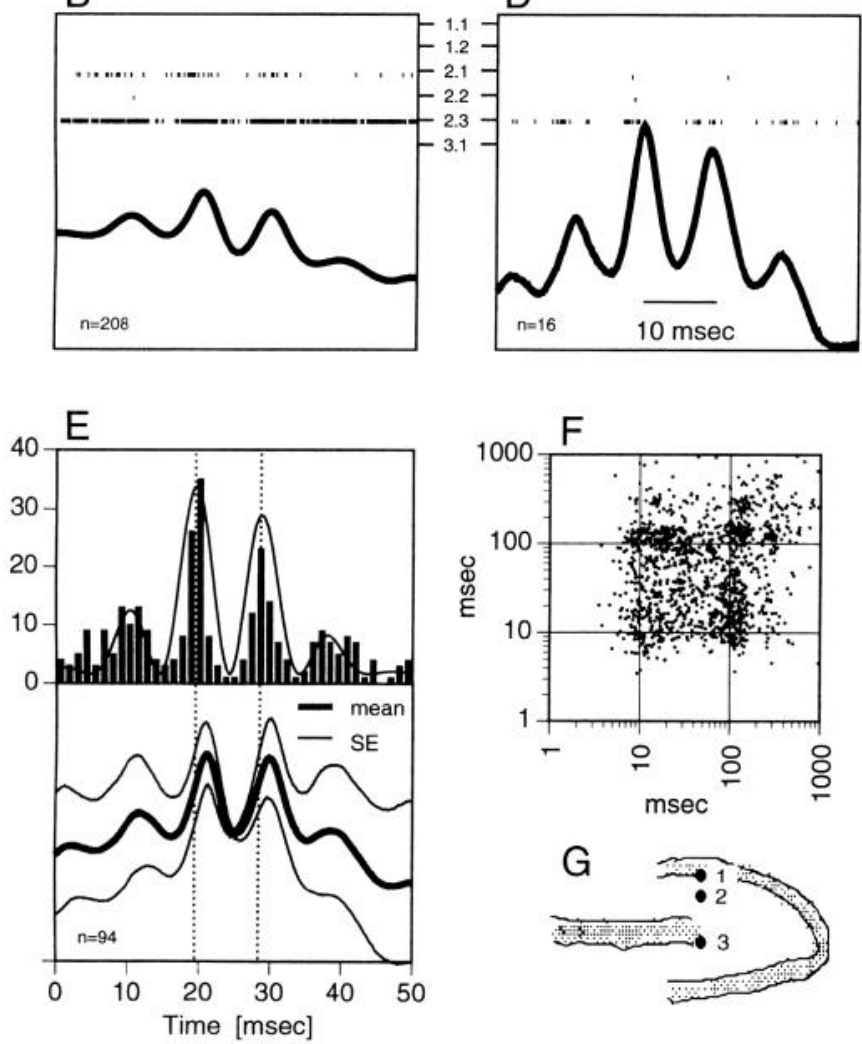

Figure 5. Relationship between gamma waves and unit activity in the dentate hilus. $A-D$, The EEG, recorded from site 2 in $G$, was filtered $(40-150 \mathrm{~Hz})$ and the resulting signals were clustered into four amplitude groups $(A-D)$. The peaks of the clustered waves were then used for averaging the wide band signal (continuous line) and for the superimposition of the discriminated units (ticks). The number of repetitions are indicated below the field averages. Neurons 1.1 to 3.1 were recorded from sites 1, 2, and 3, indicated in $F$. Site 2 yielded three separate units (2.1-2.3). Neuron 2.3 fired prior to the population spike in response to perforant path stimulation (not shown). Neuron 3.1 was a putative pyramidal neuron (complex-spike cell) and was silent during the recorded epochs. Neuron 1.1 recorded from the granule cell layer was also silent. Note increasing modulation of units with increasing amplitude of gamma waves ( $A$ to $D$ ). $E$, Unit firing histogram of unit 2.3 (above) and averaged wide field activity (bottom; SE, \pm SEM). Only epochs from $C$ and $D$ were used. Continuous line superimposed on the correlograms represents Gabor function (Engel et a., 1990). Note maximum discharge of the hilar interneuron on the ascending phase of gamma waves (dotted lines). $F$, Spike return map of interneuron firing (unit 2.3). Note high density of dots at $10 \mathrm{msec}(100 \mathrm{~Hz}$ gamma $)$ and $100 \mathrm{msec}$ (10 $\mathrm{Hz}$ theta).
A
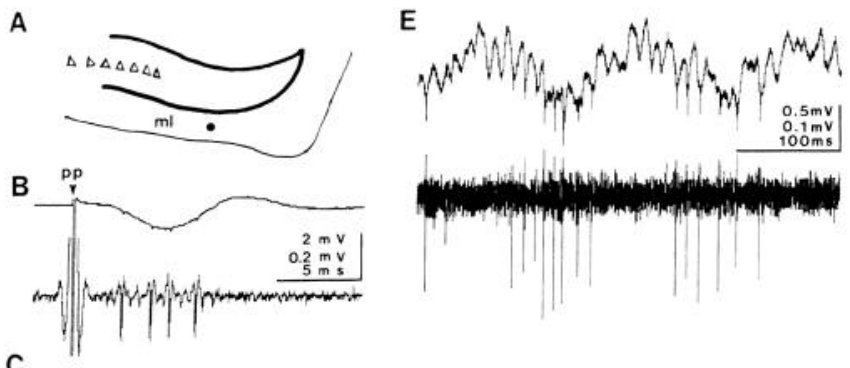

C

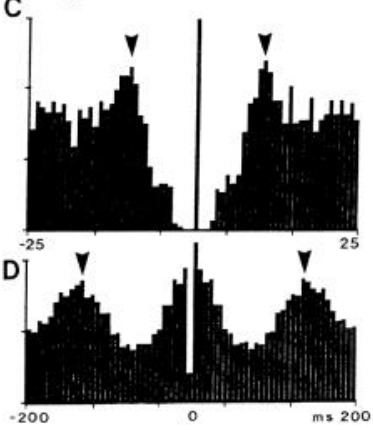

$F \quad$ random
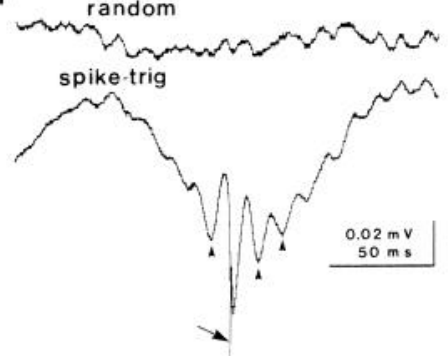

Figure 6. Interneuronal activity in relation to EEG waves. A, The recording site in the molecular layer $(\mathrm{ml})$ of the ventral leaf is indicated by a black dot. B, Low intensity stimulation of the perforant path ( $p p)$ evoked multiple discharges of the interneuron. $C$ and $D$, Autocorrelograms of the unit activity at two different time scales. Arrowheads indicate peak frequencies at around $90 \mathrm{~Hz}(C)$ and $8 \mathrm{~Hz}(D)$. Note also refractory period of 3-4 msec around the action potential $(C)$. $E$, Wide band (above) and filtered unit activity (below). Note time locked firing of the cell to both theta and fast waves. $F$, Spike-triggered (spike-trig) averages of wide-band activity. Note that unit firing (arrow) correlated with the negative-going phase of the fast waves (arrowheads). random, Average obtained by randomly shuffled pulses.

scribed above, and averaged (Fig. 5A-D). The extracellular field potentials were highly coherent at these sites and the averaged gamma waves showed a zero average time lag. The unit recorded by the upper electrode (lower part of the granule cell layer) and unit recorded by the bottom electrode (CA3c pyramidal cell layer) fired very seldom during the analyzed epoch (1 min), although they discharged in the absence of theta waves. Two of the three isolated units (units 2.1 and 2.3) recorded from the hilus proper by the middle electrode fired at high rates (10-90 $\mathrm{Hz}$ ), whereas the remaining cell (unit 2.2) was much slower. Unit 2.3 responded at 2.2 . msec latency to perforant path stimulation, that is, earlier than the granule cell population response. All three hilar units discharged phase locked to the ascending portion of the local gamma waves. Phase locking of the neurons became tighter with increasing amplitude of the local gamma waves (Fig. $5 A-D$ ). The interspike intervals of the fast hilar neurons covaried with the frequency of the locally derived gamma waves. Cross-correlation with the wide band signal revealed that these neurons were phase-locked to the positive phase of the hilar theta, as well. The remaining eight physiologically identified interneurons in other rats showed identical relationship to both gamma and theta waves. Twenty additional putative interneurons from the hilus in 15 rats also discharged on the ascending phase of the locally derived gamma waves.

One physiologically identified interneuron was found in the molecular layer (Fig. 6). The autocorrelation functions (e.g., Fig. $6 C, D)$ of the unit indicated that the cell oscillated at both theta $(8 \mathrm{~Hz})$ and gamma field frequencies $(60-80 \mathrm{~Hz})$. The neuron fired preferentially on the descending portion of the locally de- 

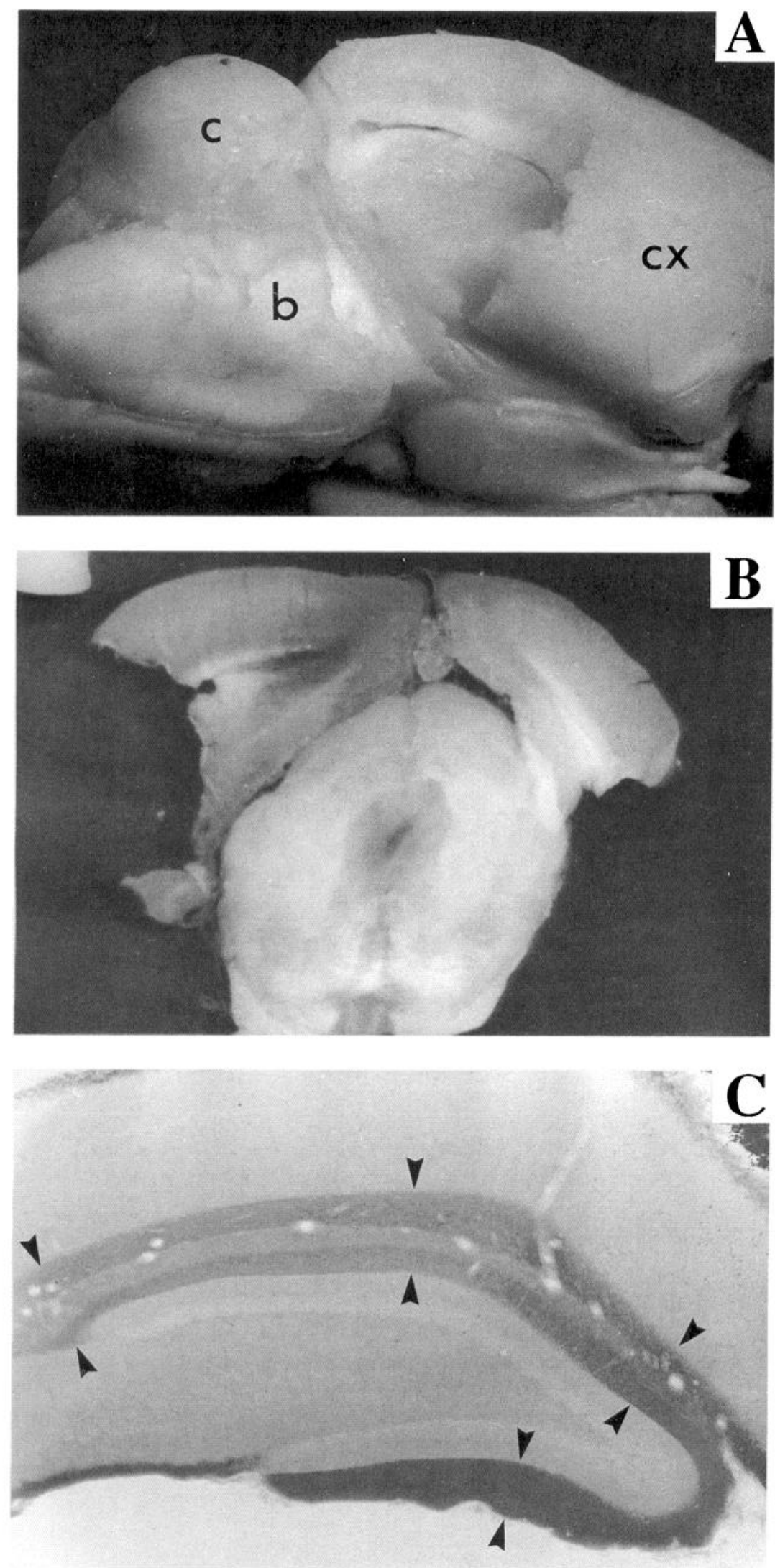

Figure 7. Entorhinal cortex lesion. A, Ventrolateral view of the brain showing the extent of the lesion, including the whole extent of the entorhinal cortex, part of the perirhinal cortex and part of the occipital cortex. $c$, Cerebellum; $b$, brainstem; $c x$, neocortex. $B$, Coronal section of the brain shown in $A$. $C$, Terminal degeneration of the perforant path fibers in the molecular layer of the dentate gyrus and in the stratum lacunosum-moleculare of $\mathrm{CA} 1$ and $\mathrm{CA} 3$ regions (arrowheads). 


\section{before}

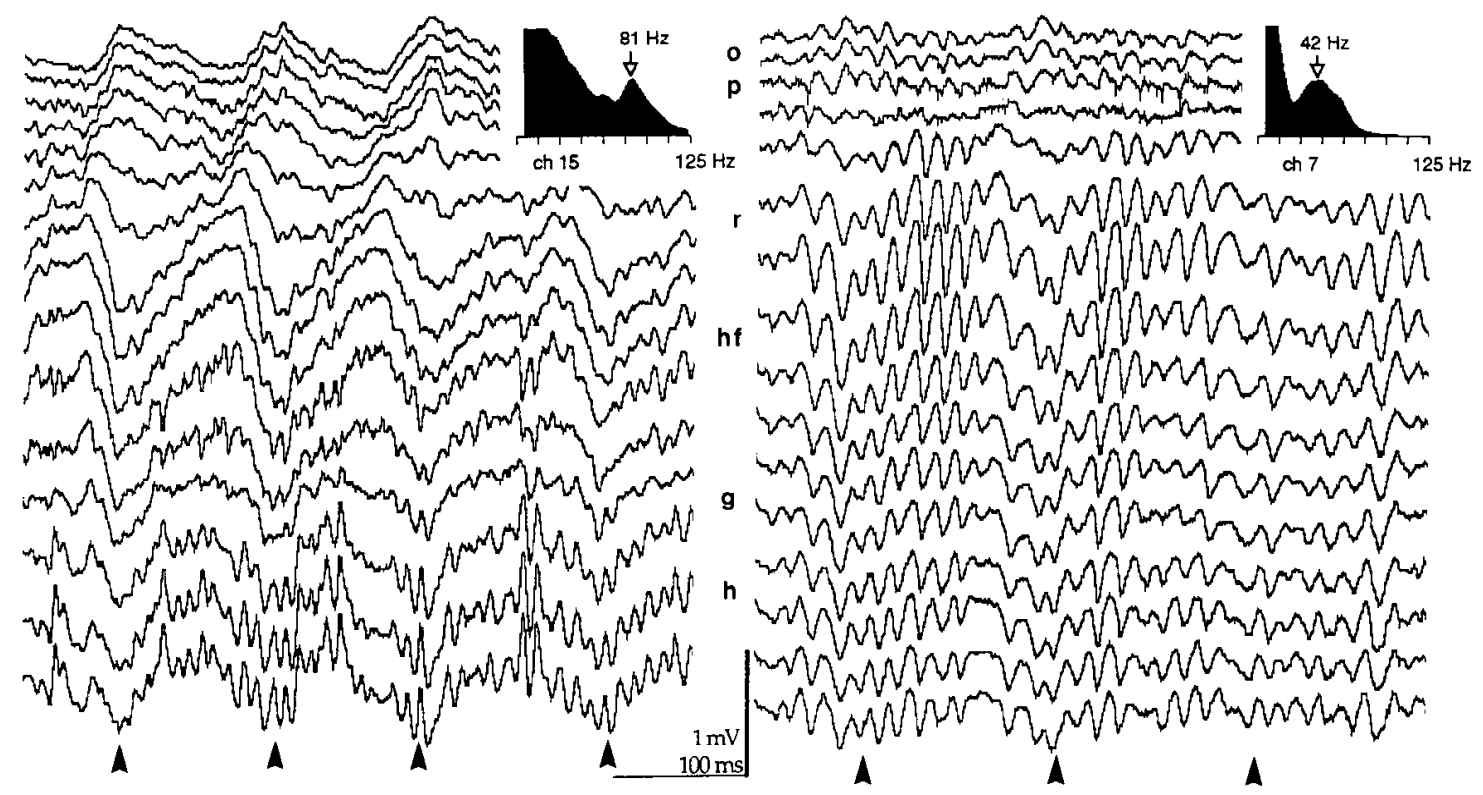

Figure 8. Field activity recorded from 16 sites in the CA1-hilus axis during walking before and $10 \mathrm{~d}$ after bilateral removal of the entorhinal cortex (EC lesion). Wide band traces $(1 \mathrm{~Hz}$ to $5 \mathrm{kHz}$ ). The third trace is from the CA1 pyramidal layer and the bottom three traces are from the hilar region. Note gradual phase shift of the slow theta waves (arrowheads) between stratum oriens $(o)$ and the hippocampal fissure ( $h f)$ in the intact animal (before). Note also that large-amplitude gamma waves (60-90 Hz) are confined to the hilus before the lesion (bottom three traces). After the lesion the amplitude of theta activity (arrowheads) decreased and gamma activity $(30-60 \mathrm{~Hz})$ became largest in the CAl stratum radiatum after the lesion (traces 6-8). Arrows in the insets indicate dominant gamma frequency. Power in the lower frequency band $(<20 \mathrm{~Hz})$ is clipped. Approximate anatomical layers are indicated between the two sets of traces. The precise relationship between recordings sites and electrical parameters is shown in Figure 9. $p, \mathrm{CAl}$ pyramidal layer; $r$, stratum radiatum; $g$, granule cell layer.

rived gamma activity (Fig. $6 F$ ). Given the $180^{\circ}$ phase reversal of the gamma waves across the granule cell layer (cf. Fig. $9 f$ ) this phase relationship corresponded to the ascending portion of hilar gamma activity.

Gamma wave modulation of complex spike cells (putative pyramidal cells or mossy cells) was more difficult to establish because of their very low firing rates. However, when multiple units were recorded by $60 \mu \mathrm{m}$ electrodes in the pyramidal layer of the CA3c subregion phase-locking of multiple unit discharges to the hilar gamma waves was observed. In three experiments hilar gamma activity was recorded simultaneously with pyramidal neurons of the CA3c-CA3b axis. Gamma wave modulation of units decreased in the hilus proper-CA3c-CA3b axis, with essentially no modulation in the $\mathrm{CA} 3 \mathrm{~b}$ region. Overall, this findings indicate that putative interneurons in the hilar region are phase locked to the local gamma waves, and that many interneurons follow the frequency shifts of gamma field oscillation in a one-to-one manner.

\section{Effect of entorhinal cortex lesion on theta and gamma field activity}

Hippocampal theta and gamma activity was monitored daily from $1 \mathrm{hr}$ to 3 weeks after the entorhinal cortex lesion in the short-term group. Histological analysis of the brains revealed that in five of the six rats the entorhinal cortex was removed completely (Fig. 7). In all cases the extent of the lesion was larger than the boundaries of the entorhinal cortex and involved damage to the perirhinal and/or occipital cortical areas, as well. Degenerating terminals of the perforant path, but not other afferents, demonstrated the specificity of the lesion (Fig. 7C).
The occasional vertical shift of the silicon probe after entorhinal cortex lesion was determined by the evoked potential profiles and unit firing in the CA1 pyramidal layer. No spontaneous afterdischarges or other aberrant patterns were present immediately after bilateral aspiration of the entorhinal cortex. However, large interictal spikes ( $>5 \mathrm{mV}$ ) occurred occasionally during immobility and slow wave sleep 1-3 d after the lesion in most rats. In addition, double pulse stimulation of the commissural path at moderate intensities induced afterdischarges in two rats. Evoked responses from both perforant path and the commissural inputs decreased immediately after $(1-5 \mathrm{hr})$ the lesion but they recovered to normal values $24 \mathrm{hr}$ later. The threshold of the perforant path response increased progressively day by day, but small-amplitude evoked field patterns were observed for 5-10 d. Importantly, the small-amplitude dentatc potentials were coupled by augmented trisynaptic responses in the CAl region. The long latency $(10-20 \mathrm{msec}) \mathrm{CAl}$ responses were present in every rat, even when virtually no evoked potentials were visible in the dentate region (see Fig. 11e).

Theta activity was present immediately after the lesion (1$24 \mathrm{hr}$ ) during explorative walking (Fig. 8) and the paradoxical phase of sleep. Howcver, the amplitude of theta was reduced by $50-70 \%$. The reduction was most prominent at the level of the hippocampal fissure and the hilar region (Fig. 9a). In the CA1 region theta waves showed a steep phase reversal across the pyramidal cell layer (Figs. $8,9 c$ ).

The large-amplitude gamma activity in the hilus, prominent in intact rats, decreased significantly. In fact, EEG records derived from the dentate molecular layer and the hilus were no longer obviously different by visual inspection (Fig. 8). In con- 
t h e t a
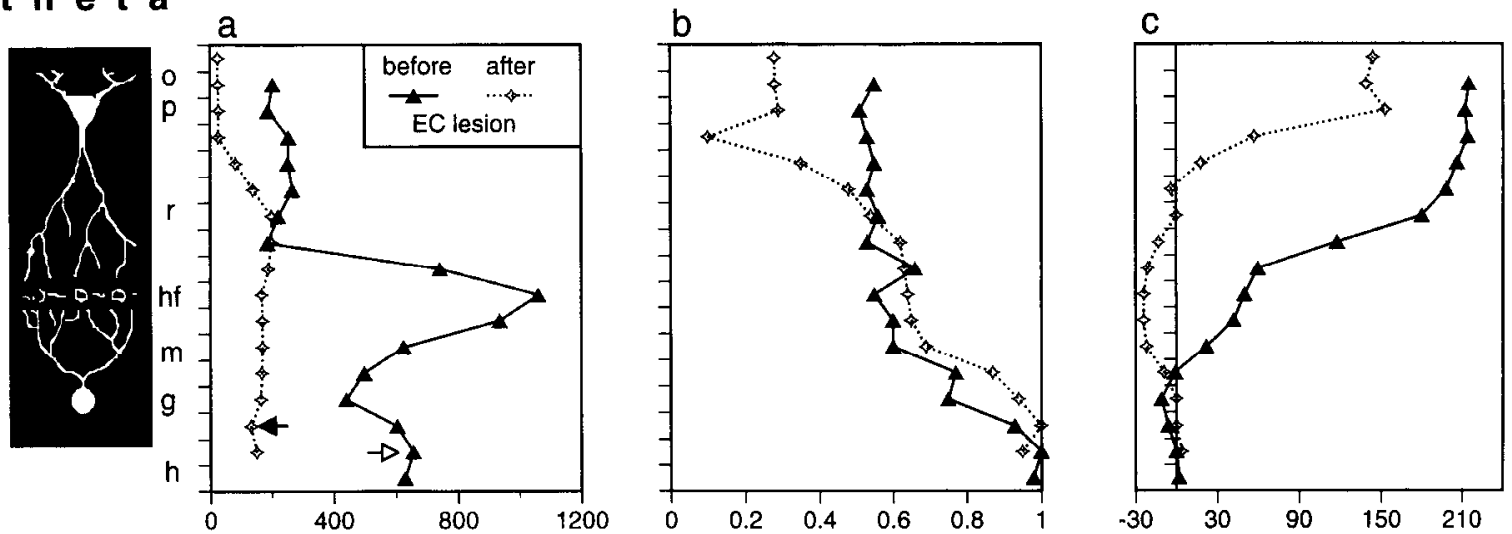

g a m m a
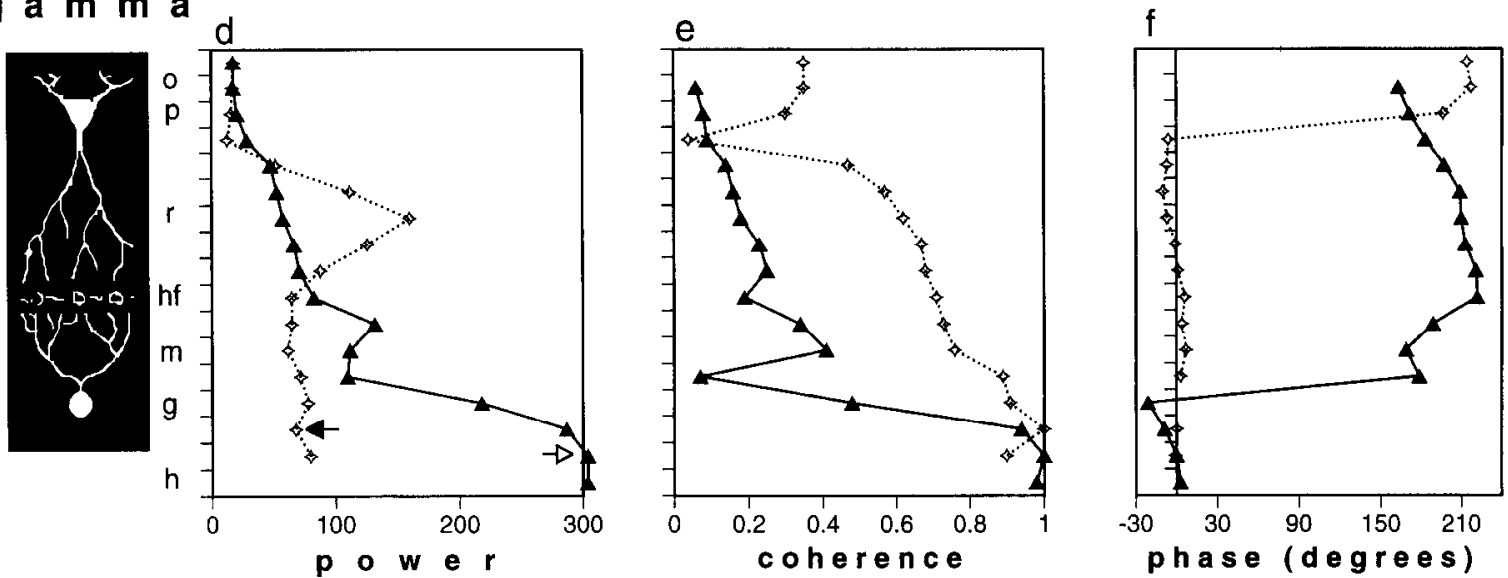

Figure 9. Depth profile changes of power, coherence and phase of theta and gamma waves after entorhinal cortex (EC) lesion. $a$, Depth profiles of theta power (integrated 6-12 hz) before and after lesion. Note lack of power maximum at the hippocampal fissure after the lesion. $b$ and $c$, Coherence and phase values, respectively, as a function of the recording depth against a hilar reference site (horizontal arrows). $d$, Power of the gamma waves (integrated $40-100 \mathrm{~Hz}$ ) at different depths. Note decreased power in the hilar region and a new peak in the CAl stratum radiatum. $e$ and $f$, Depth profiles of coherence and phase. Note higher coherence values after the lesion at all depths and rapid phase reversals of the gamma waves across the granule cell layer and the CA1 pyramidal layer before and after the lesion, respectively. The electrode shift after surgery (100 $\mu \mathrm{m}$ deeper) was compensated for by shifting the postoperative plots upward. Coherence and phase values were plotted at $80 \mathrm{~Hz}$ and $40 \mathrm{~Hz}$ before and after the lesion, respectively. The different hippocampal layers are indicated left of the ordinates in $a$ and $d$. $o$, stratum oriens; $p$, CAl pyramidal layer; $r$, stratum radiatum; $h f$, hippocampal fissure; $m$, molecular layer; $g$, granule cell layer; $h$, hilus.

trast, large-amplitude $(0.2-0.8 \mathrm{mV})$ gamma oscillations were present in the CAl region with their amplitude/power peaks in the stratum radiatum (Figs. $8,9 d$ ). Whereas before the lesion gamma waves reversed across the granule cell layer, after the lesion such a reversal was absent. Instead, a sharp phase-reversal of gamma waves occurred across the CAl pyramidal layer (Fig. $9 f$ ). The frequency of this novel gamma oscillation was significantly lower $(40-60 \mathrm{~Hz})$ than that of the hilar gamma rhythm in the intact rat. Similar to the normal animal, the power of gamma waves in the entorhinal cortex-deafferented rats was significantly larger during theta-associated behaviors than during immobility. When the amplitude of theta increased to its maximum level (e.g., during running or large-amplitude theta bursts during paradoxical phase of sleep), gamma waves, however, were attenuated. The above observations were consistent in all six rats with entorhinal cortex lesion. Pyramidal cells and putative interneurons recorded from the CA1 region of a single rat displayed a strong modulation of these cells by the local gamma field oscillation (Fig. 10).

The above observations suggested that a main source of fast waves in the entorhinal cortex damaged rat is the associational input from the $\mathrm{CA} 3$ region. This hypothesis was confirmed by the CSD analysis of the fast activity (Fig. 11). Immediately after the lesion a new large sink emerged in the stratum radiatum with a concurrent source in the pyramidal layer of the CA1 region. The CSD profile of the gamma waves in the CAl region was virtually identical with the CSD maps of sharp waves and the evoked responses mediated by the Schaffer collaterals (Fig. $11 e-h)$. The distribution of sinks and sources in the $\mathrm{CA} 1$ region were similar in all rats after the entorhinal cortex lesion. In two rats, a smaller sink-source pair was also present in the dentate gyrus in a position similar to the prelesion sink-source dipole.

In the long-term group examination of the electrical activity was carried out 3-4 months after the entorhinal cortex lesion. Since these rats were supplied with only wire electrodes, no CSD profiles were obtained. However, during exploratory activity and paradoxical phase of sleep large-amplitude gamma oscillation in the CA1 region was also present in these long-term animals. The fast oscillation often appeared as series of sharp spikes on the positive peak of theta waves recorded below the CAl pyramidal layer. These spike-like gamma waves were most prominent when theta was of relatively low amplitude and slow $(<7 \mathrm{~Hz})$. When the amplitude of theta increased to its maximum level (e.g., during fast walking) gamma waves were attenuated. 

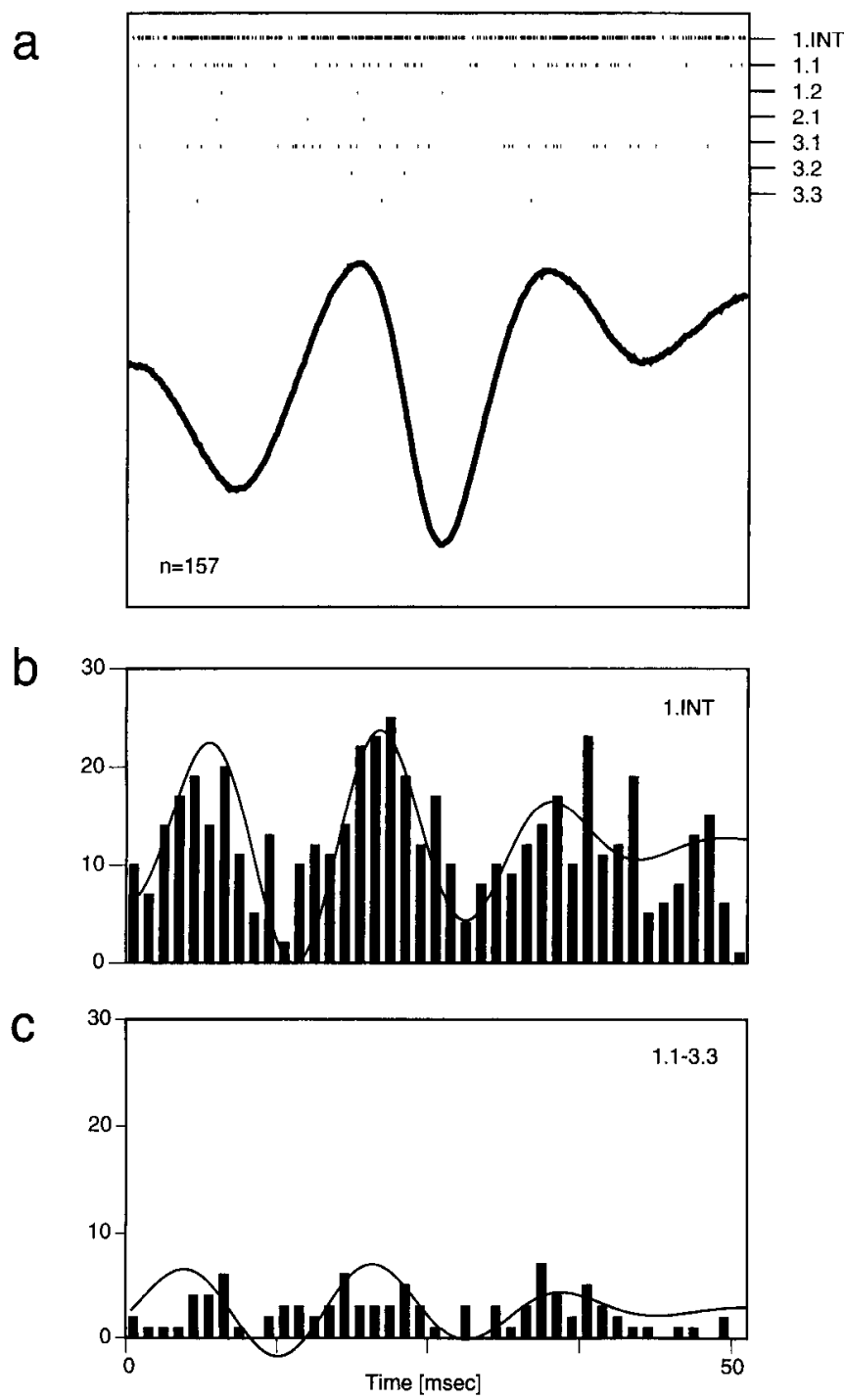

Figure 10. Gamma frequency modulation of CA1 pyramidal cells 7 $\mathrm{d}$ after removal of the entorhinal cortex. $a$, Averaged field potential ( $n$ $=157$ ) and superimposed unit activity recorded from the stratum oriens (1.INT, interneuron and units 1.1-1.2) and pyramidal layer (units 2.13.3 ) of the CA1 region. Units 1.1-3.3 are pyramidal cells recorded from three sites with $100 \mu \mathrm{m}$ intervals. $b$, Cross-correlogram of the field and interneuronal activity. $c$, Cross-correlogram of the field and summed pyramidal cell activity (1.1-3.3). Note the gamma wave modulation of both neuronal types. The lines superimposed on the correlograms represent Gabor functions that were fitted to the data to assess the depth of modulation (Engel et al., 1990).

Thus, these experiments indicate that CA3-CA1 circuitry have the capacity to oscillate at gamma frequency and this propensity is expressed immediately after removal of the entorhinal cortex. At the same time the hilar gamma oscillator disappears or remains strongly attenuated.

\section{Discussion}

The main findings of the present experiments are that (1) the largest amplitude of gamma oscillation occurs in the dentate region, (2) gamma waves are coherent along the longitudinal axis of the hippocampus, (3) an important electromotive force for the fast activity is the entorhinal input, (4) gamma patterns are modulated by theta activity, and (5) the dominant source of gamma activity after removal of the entorhinal input is the CA3 region.

Afferents to the middle and outer thirds of the molecular layer of the dentate gyrus arise from the layer II stellate cells of the medial and lateral entorhinal cortex, respectively (Steward, 1976). CSD analysis of gamma waves identified a distinctive sink in the middle third of the molecular layer during theta-associated behaviors. The power and frequency of gamma activity substantially decreased in the dentate gyrus following surgical removal of the entorhinal cortex. On the other hand, high-frequency activity in the hilar region survived after septal lesion (Stumpf, 1965) and after the transection of the fimbria-fornix (Buzsáki et al., 1987) despite complete elimination of theta activity. These findings are compatible with the view that the perforant path synapses on the dendrites of granule cells and hilar neurons play an important role in the generation of gamma field activity. In line with this suggestion are the observations that gamma field oscillation and associated firing of neurons are present in the superficial layers of the entorhinal cortex of the anesthetized rat (Charpak et al., 1992) and awake cat and rat during theta behaviors (Boeijinga and Lopes da Silva, 1988; Chrobak et al., 1993). However, other findings of the present experiments argue against a single rhythm generator (entorhinal cortex)-passive follower (hippocampus) model of gamma oscillation (see below).

\section{Extracellular currents associated with gamma oscillation}

Based on the close correspondence between extracellular negativity and a large sink of the gamma oscillation in the middle molecular layer, we assume that extracellular negativity at this level reflects synchronous depolarization of granule cells by the entorhinal input. In principle, some of our unidentified neurons could have been activated granule cells which, in turn, recurrently excited hilar interneurons. Based on such a scenario it is expected that interneurons should discharge after the maximum depolarization and discharge of granule cells, that is, on the positive peak or the descending part of the hilar gamma waves. In contrast to this model, all putative interneurons in our study fired on the ascending part of gamma waves, that is prior to the discharge of granule cells. These neurons could therefore be driven monosynaptically by layer II stellate cells of the entorhinal cortex. Indeed, several hilar cells extend dendrites into the molecular layer of the dentate gyrus (Amaral, 1978) and putative basket cells and hilar interneurons responded earlier and at a lower current threshold than the granule cell population spike evoked by stimulation of the perforant path. The feed-forward activation of interneurons (Buzsáki and Eidelberg, 1982) is further supported by the neuron recorded in the molecular layer which fired at the same phase of gamma waves as the putative interneurons in the hilus and was shown to be directly excited by perforant path stimulation. Since axon collaterals of granule cells do not return to the molecular layer (Amaral, 1978; Claiborne et al., 1986), a likely driving source of this neuron is the perforant path.

Independent of whether basket cells and hilar interneurons are activated by the perforant path, granule cells, or by other means, their terminals on the somatic/perisomatic region of granule cells will produce periodic inhibition of the latter neurons. In accordance with this suggestion, several types of hilar neurons are known to provide inhibition on the somata, proximal dendrites and axon initial segment of the granule cells (Ramón y Cajal, 1911; Halasy et al., 1993; Han et al., 1993). 


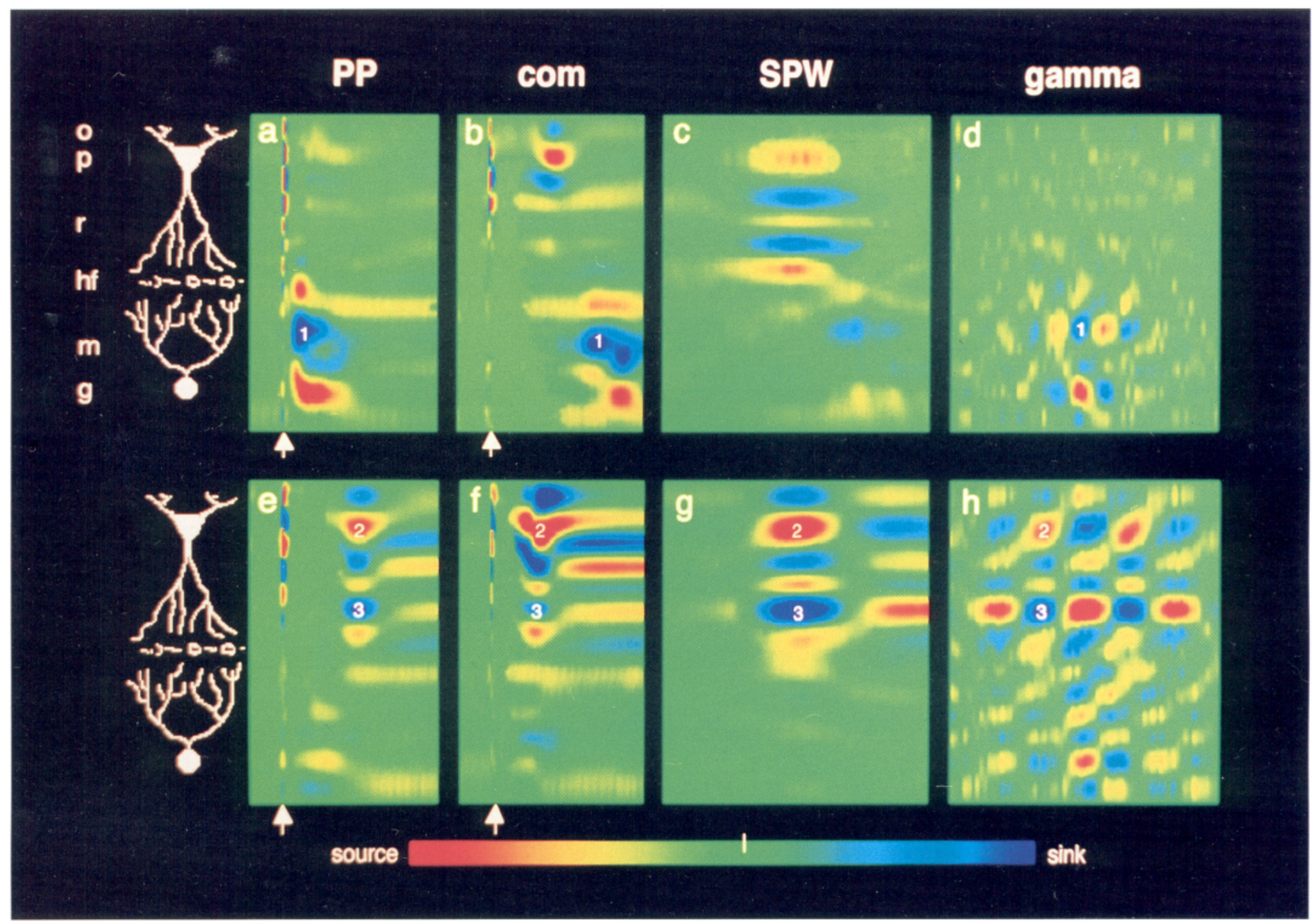

Figure 11. CSD maps of evoked and spontaneous field patterns before $(a-d)$ and $2 \mathrm{~d}$ after $(e-h)$ bilateral lesion of the entorhinal cortex. Arrows, Stimulation of the perforant path $(P P)$ and commissural $(\mathrm{com})$ inputs. Before the lesion stimulation of the commissural fibers triggered a polysynaptic (CA1-subiculum-entorhinal cortex) response in the dentate gyrus (sink 1 in $b$ ) which is missing even at twice the stimulus intensity after the lesion $(f)$. The monosynaptic dentate response to PP is attenuated after the lesion but polysynaptic activation of the Schaffer collaterals (sink 3 in $e$ and $f$ ) is accentuated. SPWs have the same sink-source positions ( 2 and 3$)$ before and after EC damage. In contrast, gamma wave (filtered $40-150 \mathrm{~Hz}$ in $d$ and $30-90 \mathrm{~Hz}$ in $h$ ) current distribution is different. Note the newly emerged sink-source pair in the CA1 region after the lesion ( 2 and 3 in $h)$. Note also the similar laminar distribution of sink-source pairs in the CA1 region for gamma activity $(d)$, SPW $(g)$ commissural stimulation $(f)$ and polysynaptic activation of the Schaffer collaterals $(e)$ after the lesion. Color scaling is the same before and after the lesion. $O$, Stratum oriens; $p$, CAl pyramidal layer; $r$, stratum radiatum; $h f$, hippocampal fissure; $m$, molecular layer; $g$, granule cell layer.

A logical progress of thought from these observations is that at least part of the extracellular current flow, associated with the source in the granule cell layer, arises from synchronously active IPSCs on the granule cells. Since all fast firing interneurons were phase locked to the ascending portion of the hilar gamma waves, it is expected that they provide a concerted inhibition to their main targets, that is, the granule cells, mossy cells and CA3 pyramidal cells (Han et al., 1993). This would explain why complex spike neurons in the hilar region (putative mossy cells and pyramidal cells) were mostly silent during theta-associated gamma oscillation. In line with this suggestion, it was shown recently that pyramidal neurons possess $\mathrm{Cl}^{-}$-mediated rhythmic IPSPs phase locked to the hilar fast activity in ketamine anesthetized rats (Soltész and Deschénes, 1993). Overall, these findings suggest that the extracellularly observed gamma waves reflect summation of rhythmic EPSPs by the perforant path input at the dendrites (active inward currents) and IPSPs by the oscillating interneurons at the somata (active outward currents) of the orderly aligned granule cell population. Given the spatial segregation of the inward and outward currents (dendrites vs somata), these active currents would summate in the extracellular space.

\section{Emergence and spatial coherence of the hippocampal gamma rhythm}

As discussed above, several of our observations are compatible with the view that the entorhinal input to the dentate gyrus plays a pivotal role in both the rhythm and current generation of gamma oscillation. However, the findings that removal of the entorhinal cortex enhanced the power of oscillations in the CA3-CA1 circuitry and that at least some gamma oscillation survived in the dentate hilus argues against the hypothesis that the entorhinal cortex simply imposes its rhythm on a passive network in the dentate gyrus. Putative interneurons of the hilar region discharged coherently with the fast gamma field and contributed actively to the extracellular currents. The rhythmic discharge of these neurons may have resulted from either their network-driven excitation, intrinsic oscillatory properties or both. 
It has recently been shown that the membrane potential of sparsely spiny inhibitory interneurons in cortical layer IV can sustain a $40 \mathrm{~Hz}$ oscillation by sequential activation of a persistent sodium current followed by a slowly inactivating potassium conductance (Llinás et al., 1991; Wang, 1993). Intrinsic oscillatory properties have also been shown in the intralaminar thalamocortical neurons (Steriade et al., 1993) and GABAergic cells of the nucleus reticularis thalami in vivo (Pinault and Deschenes, 1992). Although neurons with similar intrinsic oscillatory properties have yet to be demonstrated in the hippocampus, it may be hypothesized that tonic depolarization of interneurons would give rise to intrinsic oscillation at $40-100 \mathrm{~Hz}$ during theta activity. Candidate depolarizing inputs during theta activity are the septohippocampal cholinergic fibers and the perforant path. Cholinergic fibers have been shown to terminate on both principal cells and interneurons (Léránth and Frotscher, 1987) and ACh is known to excite interneurons (cf. McCormick, 1992). The importance of the excitatory perforant path is demonstrated by the findings that the power of gamma oscillation in the hilus decreased significantly after bilateral removal of the entorhinal cortex but survived after surgical removal of the subcortical inputs to the hippocampus (Buzsáki et al., 1987). Another important input to the hippocampal interneurons is the septohippocampal GABAergic pathway. These GABAergic fibers terminate exclusively on interneurons and each fiber can contact the postsynaptic targets by several synapses (Freund and Antal, 1988). Since this pathway provides a rhythmic hyperpolarization of the interneurons at theta frequency (Stewart and Fox, 1990), the hypothesized voltage-dependent gamma oscillation of hippocampal interneurons will be periodically interrupted. Such an interaction of the depolarization forces and rhythmic inhibition can explain the observed phase locking of interneurons to both theta and gamma oscillations. Such coupling has two advantages. First, the oscillatory process will keep the principal cells in a "readiness" state by keeping their membrane potential close to, but below, the threshold for action potential generation. Second, by the periodic modulation of the membrane potential the sluw and intermittently firing principal cells can be activated in a time-locked manner by relatively weak excitation.

A striking finding of the present experiments was the highly coherent theta and gamma activity in the hilus along the longitudinal axis of the hippocampus. This can be contrasted with the fast decay of coherence from the hilus towards the CA3 region or upward above the granule cell layer. Phase locking of spatially distributed interneurons into the network oscillation can occur via reciprocal connections between interneurons, hilar mossy cells and CA3 pyramidal neurons. Both mossy cells and pyramidal cells of the CA $3 \mathrm{c}$ subregion project their axons in the longitudinal direction and establish numerous contacts with each other as well as with the interneuron population of the hilar region (Amaral, 1978; Li et al., 1994). In turn, axon collaterals of some hilar interneurons span $400-800 \mu \mathrm{m}$ in the longitudinal axis (Han et al., 1993; our unpublished findings). Despite the significant conduction delays in these collaterals, synchronization with zero average phase lag can be brought about by reciprocal interactions of the participating neurons. When a critical number of spatially distributed interneurons discharge at approximately $40-100 \mathrm{~Hz}$ during gamma oscillation, they will affect the timing of the action potentials in their common mossy cell and pyramidal cell targets. In turn, the concurrently discharging few mossy cells and/or pyramidal cells will reset the phase of the intrinsic oscillation of their common target interneurons in the next cycle(s), thereby establishing a highly coherent, spatially distributed rhythmic inhibition in a large number of granule cells. Thus, by means of spatial divergence and converging overlap of connections between mossy cells and interneurons phase locking of interneuronal action potentials can be established. In this scenario no particular site is leading the oscillation, since interneuronal synchrony is not determined by location or a rhythmic perforant path drive but by the temporal coincidence of the discharging mossy/pyramidal cells.

Activity in perforant path fibers can have two interdependent effects on the gamma oscillation in the dentate gyrus. First, by providing a diffuse "background" excitation the depolarization level of the interneurons is increased, resulting in higher frequency firing and recruitment of more interneurons into the oscillatory mode. The consequence is a larger power and faster gamma oscillation. The observation that both the power and frequency of gamma oscillation decreased significantly after bilateral removal of the entorhinal cortex supports such a view. Second, the rhythmic output from the entorhinal cortex can entrain the dentate oscillator into a phase locked, coherent oscillation. This second mechanism is likely since neurons in layer II of the entorhinal cortex significantly increase their firing rates during theta-associated behaviors and fire rhythmically at gamma frequency (Charpak et al., 1992; Quirk et al., 1992; Chrobak et al., 1993). Thus, it appears that the dentate circuitry is tuned to oscillate best in the frequency range it naturally receives from its entorhinal input.

Gamma oscillation in the CA3-CAl network is a rare event in the intact animal, as evidenced by the lack of a significant gamma dipolc in the CAl region and the low coherence values between the dentate hilus and CA3-CAl regions. That the latter network can display oscillation in the gamma frequency range is illustrated by the high power of gamma and phase-locked discharge of CAl neurons to the gamma waves following the entorhinal cortex lesion as well as the transient increases of coherence between the hilar and CAl regions in the intact rat. These observations suggests that under physiological conditions the hilar region output exerts a tonic inhibitory influence on the CA3 network and thereby prevents the emergence and maintenance of gamma oscillation in the CA3-CAl circuitry.

\section{Possible physiological function of gamma activity}

Synchronous gamma activity has been extensively studied in various structures of the brain (Freeman and Skarda, 1985; Gray et al., 1989; Gray, 1993, 1994; Llinás and Ribary, 1993; Freeman, 1994; Singer, 1994). Mainly in association with visual processing, it has been hypothesized that binding and segmentation in perception are dynamically encoded in the temporal relationship between coactivated neurons. The basic tenet of the temporal binding hypothesis is that temporal conjunction of neurons activated by the various aspects of visual modality (shape, color, position, direction of movement, etc.) represent the subjective experience referred to as percept (Gray et al., 1989). If gamma oscillations in the neocortical areas and the hippocampal gamma pattern are related, we may hypothesize that coherent oscillation of neocortical and hippocampal neurons may reflect the fusion of currently perceived and stored attributes of objects and events. In this context, the gamma pattern is viewed as a carrier wave which ensures the temporal conjunction of the aperiodically active, slow discharging principal cells of the hippocampus and neocortex. Such temporal 
coherence of neuronal firing in neocortical and limbic areas could explain how sensory cues can assist memory retrieval as well as how perceived and stored features of the external world can be linked.

\section{References}

Amaral DG (1978) A Golgi study of cell types in the hilar region of the hippocampus in the rat. J Comp Neurol 182:851-914.

Bland BH (1990) Physiology and pharmacology of hippocampal formation theta rhythms. Prog Neurobiol 26:1-54.

Boeijinga PH, Lopes da Silva F (1988) Differential distribution of $\beta$ and $\gamma$ EEG activity in the entorhinal cortex of the cat. Brain Res 448: 272-286.

Bragin A, Jando $G$, Horvath $L$, Buzsáki $G$ (1992) The dentate spike: a new network pattern reflecting interneuronal synchrony. Soc Neurosci Abstr 141.11.

Bragin A, Jandó G, Nádasdy Z, Hetke J, Wise K, Buzsáki G (1993) Gamma frequency $(40-100 \mathrm{~Hz})$ patterns in the hippocampus: modulation by theta activity. Soc Neurosci Abstr 148.3.

Brankack J, Stewart M, Fox SE (1993) Current source density analysis of the hippocampal theta rhythm: associated sustained potentials and candidate synaptic generators. Brain Res 615:310-327.

Bullock TH, Buzsáki G, McClune MC (1990) Coherence of compound field potentials reveals discontinuities in the CA1-subiculum of the hippocampus in freely-moving rats. Neuroscience 38:609-619.

Buzsáki G (1986) Hippocampal sharp waves: their origin and significance. Brain Res 398:242-252.

Buzsáki $G$, Czéh $G$ (1992) Physiological function of granule cells: a hypothesis. In: The dentate gyrus and its role in seizures (Ribak CE, Gall CM, Mody I, eds), pp 281-290. Amsterdam: Elsevier.

Buzsáki G, Eidelberg E (1982) Direct afferent excitation and long-term potentiation of hippocampal interneurons. J Neurophysiol 48:597607.

Buzsáki G, Leung L, Vanderwolf CH (1983) Cellular bases of hippocampal EEG in the behaving rat. Brain Res Rev 6:139-171.

Buzsáki G, Czopf J, Kondakor I, Kellenyi L (1986) Laminar distribution of hippocampal rhythmic slow activity (RSA) in the behaving rat: current source density analysis, effects of urethane and atropine. Brain Res 365:125-137

Buzsáki G, Gage FH, Czopf J, Björklund A (1987) Restoration of rhythmic slow activity (theta) in the subcortically denervated hippocampus by fetal CNS transplants. Brain Res 400:334-347.

Buzsáki G, Bickford RG, Ryan LJ, Young S, Prohaska O, Mandel RJ, Gage FH (1989) Multisite recording of brain field potentials and unit activity in freely moving rats. J Neurosci Methods 28:209-217.

Buzsáki G, Horváth Z, Urioste R, Hetke J, Wise K (1992) Highfrequency network oscillation in the hippocampus. Science 256:10251027.

Chang Y, Fu K (1985) Conceptual clustering in knowledge organization. IEEE Trans Patt Anal Mach Intell 7:592-598.

Charpak S, Pare D, RR Llinás (1992) Entorhinal cortex (EC) generates $40 \mathrm{~Hz}$ hippocampal oscillations. Soc Neurosci Abstr 386.5.

Chrobak JJ, Buzsáki G (1994) Selective activation of deep layer retrohippocampal neurons during hippocampal sharp waves. J Neurosci, in press.

Claiborne BJ, Amaral DG, Cowan WM (1986) A light and electron microscopic analysis of the mossy fibers of the rat dentate gyrus. $J$ Comp Neurol 246:435-458.

Engel AK, Koenig P, Gray CM, Singer W (1990) Stimulus-dependent neuronal oscillations in the cat visual cortex: inter-columnar interaction as determined by cross-correlation analysis. Eur J Neurosci 2:588-606.

Fox SE, Ranck JB Jr (1981) Electrophysiological characteristics of hippocampal complex-spike cells and theta cells. Exp Brain Res 41: 299-313.

Fox SE, Ranck JB Jr (1986) Hippocampal theta rhythm and the firing of neurons in walking and urethane anesthetized rats. Exp Brain Res 62:495-508.

Freeman WJ (1994) Chaotic oscillation and genesis of meaning in the cerebral cortex. In: Temporal coding in the brain (Buzsáki $\mathrm{G}$, Llinâs R, Singer W, Bethoz A, Christen Y, eds), in press. Berlin: Springer.

Freeman WJ, Skarda CA (1985) Spatial EEG patterns, nonlinear dynamics and perception: the neo-Sherringtonian view. Brain Res Rev 10:147-175.
Freund TF, Antal M (1988) GABA-containing neurons in the septum control inhibitory interneurons in the hippocampus. Nature 336:170173.

Gallyas F, Güldner F, Zoltay G, Wolff J (1990) Golgi-like demonstration of "dark" neurons with an argyrophil III method for experimental neuropathology. Acta Neuropathol (Berl) 79:620-628.

Gray CM (1993) Rhythmic activity in neuronal systems: insights into integrative function. In: SFI studies in the sciences of complexity, Lectures in complex systems (Nadel L, Stein D, eds), pp 89-161. Reading, MA: Addison-Wesley.

Gray CM (1994) Synchronous oscillations in neuronal systems: mechanisms and function. J Comput Neurosci, in press.

Gray CM, Koenig P, Engel AK, Singer W (1989) Stimulus-specific neuronal oscillations in cat visual cortex exhibit inter-columnar synchronization which reflects global stimulus properties. Nature 338: 334-337.

Halasy K, Somogy P (1993) Subdivision in the multiple GABAergic innervation of granule cells in the dentate gyrus of the rat hippocampus. Eur J Neurosci 5:411-429.

Han Z-S, Buhl EH, Lörinczi Z, Somogyi P (1993) A high degree of spatial selectivity in the axonal and dendritic domains of physiologically identified local-circuit neurons in the dentate gyrus of the rat hippocampus. Eur J Neurosci 5:395-410.

Léránth C, Frotscher M (1987) Cholinergic innervation of hippocampal GAD- and somatostatin-immunoreactive commissural neurons. J Comp Neurol 261:33-47.

Leung LS (1979) Potentials evoked by alvear tract in hippocampal CAl region of rats. I. Topographical projection, component analysis, and correlation with unit activities. J Neurophysiol 42:1557-1570.

Leung LS (1992) Fast (beta) rhythms in the hippocampus: a review. Hippocampus 2:93-98.

Leung LS, Lopes da Silva FH, Wadman WJ (1982) Spectral characteristics of the hippocampal EEG in the freely moving rat. Electroencephalogr Clin Neurophysiol 54:203-219.

Li X-G, Somogyi P, Ylinen A, Buzsáki G (1994) The hippocampal CA3 network: an in vivo intracellular labeling study. J Comp Neurol 339:181-208.

Llinás R, Ribari U (1993) Coherent $40-\mathrm{Hz}$ oscillation characterizes dream state in humans. Proc Natl Acad Sci USA 90:2078-2081.

Llinás RR, Grace AA, Yarom Y (1991) In vitro neurons in mammalian cortical layer 4 exhibit intrinsic oscillatory activity in the 10to $50 \mathrm{~Hz}$ frequency range. Proc Natl Acad Sci USA 88:897-901.

McCormick DA (1992) Neurotransmitter actions in the thalamus and cerebral cortex and their role in neuromodulation of thalamocortical activity. Prog Neurobiol 39:337-388.

Mizumori SJY, McNaughton BL, Barnes CA, Fox KB (1989) Preserved spatial coding in hippocampal CAl pyramidal cells during reversible suppression of CA3 output: evidence for pattern completion in hippocampus. J Neurosci 9:3915-3928.

Pinault D, Deschenes M (1992) Voltage-dependent 40-Hz oscillations in rat reticular thalamic neurons in vivo. Neuroscience 51:245-258.

Quirk GJ, Muller RU, Kubie JL, Ranck JB Jr (1992) The positional firing properties of medial entorhinal neurons: description and comparison with hippocampal place cells. J Neurosci 12:1945-1963.

Ramón y Cajal S (1911) Histologie du systéme nerveux de l'homme et des vertebrés. Paris: Maloine.

Ranck JB Jr (1973) Studies on single neurons in dorsal hippocampal formation and septum in unrestrained rats. I. Behavioral correlates and firing repertoires. Exp Neurol 42:461-531.

Siegel RM (1990) Non-linear dynamical system theory and primary visual cortical processing. Physica [D] 42:385-395.

Singer W (1993) Synchronization of cortical activity and its putative role in information processing and learning. Annu Rev Physiol 55: 349-374.

Skaggs WE, McNaughton BL, Barnes CL (1991) 40-Hz "fluttering" oscillation in the rat hippocampus. Soc Neurosci Abstr 17:1395.

Soltesz I, Deschenes M (1993) Low- and high-frequency membrane potential oscillations during theta activity in CAl and CA3 pyramidal neurons of the rat hippocampus under ketamine-xylazine anesthesia. $\mathrm{J}$ Neurophysiol, in press.

Soltész I, Bourassa J, Deschénes M (1993) The behavior of mossy cells of the rat dentate gyrus during theta oscillations in vivo. Neuroscience 57:555-564.

Steriade M, McCormick DA, Sejnowski TJ (1993) Thalamocortical oscillations in the sleeping and aroused brain. Science 262:679-685. 
Steward O (1976) Topographic organization of the projections from the entorhinal area to the hippocampal formation of the rat. J Comp Neurol 167:285-314.

Stewart M, Fox SE (1990) Do septal neurons pace the hippocampal theta rhythm? Trends Neurosci 13:163-168.

Stumpf C (1965) Drug action on the electrical activity of the hippocampus. Int Rev Neurobiol 8:77-138.

Wang X-J (1993) Ionic basis for intrinsic $40 \mathrm{~Hz}$ neuronal oscillations Neuroreport 5:221-224.
Wise KD, Najafi K (1991) Microfabrication techniques for integrated sensors and microsystems. Science 254:1335-1342.

Yang X (1988) A totally automated system for detection and classification of neural spikes. IFFE Trans Biomed Eng 35:806-816.

Ylinen A, Bragin A, Nádasdy Z, Jandó G, Szabó I, Sik A, Buzsáki G (1994) Sharp wave-associated high-frequency oscillation $(200 \mathrm{~Hz})$ in the intact hippocampus: network and intraccllular mechanisms. J Neurosci $14: 30-46$. 